\title{
TRANSLATION CRITICISM AS A MEASURE OF LINGUISTIC COHERENCE IN THE TRANSLATION PROCESS
}

\author{
Tetiana Boiko \\ Assistant Professor, PhD, Taras Shevchenko National University of Kyiv, \\ e-mail: tanjabojko@ua.fm, orcid.org/0000-0002-6088-7243, Ukraine \\ Khrystyna Melko \\ Assistant Professor, PhD, Kyiv National Linguistic University, \\ e-mail: chmelko@ukr.net, orcid.org/0000-0002-3384-7529, Ukraine
}

\begin{abstract}
The article is focused on the ways of realization translation criticism in the modern translation studies. The main aim for the translators in their works is to achieve linguistic coherence between the Source Text (ST) and Target Text (TT). The notion of translation criticism, which is an important measure of achieving this goal by the translator, is highlighted. The theory of scenes and frames in modern translation studies is also analysed in the article.
\end{abstract}

Keywords: translation criticism, linguistic coherence, scenes-and-frames theory, translation studies.

DOI: http://dx.doi.org/10.23856/3609

\section{Introduction}

Translation criticism is a systematic study and sometimes forgotten element of the translation process. This article is focused on explaining the notion of translation criticism and its role in modern translation studies. Different theories and viewpoints have been pointed out on this topic. Some exemplary models of translation criticism are given in order to analyse the main feature of this linguistic process. The theory of scenes and frames is stated as one of the important theory in translation criticism, and the linkage between translation criticism and this theory has been described in the article. The aims involved in translation criticism is to make the society aware of the delicacy involved in the process of translation. Translation criticism is one of the most required elements of the translation process, coherence has also been connected with the topic of translation criticism, this is a great measure of translator's work and the final effect of the translation process.

\section{The notion of translation criticism and its key features}

For hundreds of years translators have played a major role in the mankind communication. Translation Studies, a concept that consists of "translation theory, translation production" and "translation product", is often focused on different processes and methods that constitute translation (Valero, 1995). Different points of view have emerged in this field and some of them showed the necessity to "combine and connect" all of the translational aspects (Lambert, Van Gorp, 1985:50). One of these aspects can be viewed as Translation Criticism (TC) as an individual "research field" (Valero, 1995).

Taking translator's work into consideration, "translating is a decision process", which means it consists of various situations that can also be called "moves" (Levý, 2004: 148). A 
translator can decide how many moves he will make and needs to make other important decisions in his translation process. TC should be taken seriously as one of such moves, especially when we are talking about literary translation. "Translation can be seen as a problem-solving activity in which a source element may be rendered by one or more elements in the target language" (Babelyuk, Galaidin, 2018: 99). We should remember that in the translation process some "special strategies, procedures, techniques ant methods" are necessary (Babelyuk, 2017: 23). It is clear, however, that different types of translated texts have different rules and are treated disparately. There is also no stated standard for translation - depending on the purpose, the effect of a translation process can be better or worse. The role of TC is to define this effect as a more or less coherent and to observe different processes appearing in it.

The beginning of a critics work starts from understanding how to criticize a translation and be familiar with the main points involved in the act of criticizing. If it is done in its own right and proper way, and is based on some identifiable principles, it will lead to great developments in the field of translation studies. If our criticism is based on logic, it will help the translators to better improve their competence of the two languages and to better improve their potency in rendering a text.

There are different opinions on TC. At least one of them "has suggested that" it should "be considered a separate area of applied translation studies" (Maier, 2009: 237). Some others claim that TC "is an essential link between translation theory and its practice" (Newmark, 1988: 184) or that it allows to realize the truth of a translation. One of TC models was described by Hans J. Vermeer as 3 important steps: 1) to analyse the TT in order to decide whether it "fulfils the aims declared by the translator"; 2) to analyse the ST's intentions; 3 ) to compare both texts "by reference to their (possibly different) aims" (Vermeer, 1998: 63). A more developed theory by Margret Ammann consists of 5 tasks: 1) to establish the "function of the translation in the target culture"; 2) to determine the translation's coherence; 3) to analyse ST's function "in the source culture"; 4) to determine the ST's coherence; 5) to compare the "intertextual coherence" between ST and TT (Snell-Hornby, 2006: 110). Although this model of TC applies to literary texts, it can also be used according to nonfiction.

All of these available models of TC require a talented and experienced critic, which should be done by a translator. In this process, however, the critic is not focused on translating one text into another. Instead, he is "confronted with . . . two completed communication situations" (Valero, 1995), so he is simultaneously the receiver of the ST and TT. Both of these texts are sometimes referred to as LC1 and LC2. The Translation Critic needs to use the right methods in order to establish both texts' functions, culture and coherence. This task can be fulfilled by analysing LC1 and LC2 separately and comparing them in the end. Valero (1995) also highlights the role of two important factors of TC: the Translation Initiator (TI) and the Translation Operator (TO). Both of them have a great impact on the effect of translation, but it is the Translation Critic which has to deal with "unpleasant problems" (Valero, 1995). Its task is not to indicate possible differences between ST and TT, but to assess the translation's coherence and to be objective in this process. The TC is still a field that needs more research, and the existence of "numerous and diverse criteria and approaches offers a challenge to contemporary critics, readers and translators" (Maier, 2009:240). 


\section{The theory of scenes and frames}

The theory of scenes and frames has a close connection with the topic of TC, for it was an inspiration for further research of scholars such as M. Ammann. This theory was introduced by an American linguist, Charles J. Fillmore. The scenes and frames approach is based on perceiving the translation process as "a complex act of communication involving interaction between the author of the source text, the translator as both source text reader and target text author, and then the reader of the source text" (Snell-Hornby, 2006: 110). Particular elements of the translation process can be described as frames. The ST, which is a starting point for the translator, is a frame itself, but also its linguistic components can be called frames. The notion of frames is explained by Ch. J. Fillmore on an example of a child, who learns new words in particular situations. When a child hears the word "pencil", it may associate it with a particular experience, for example his mother drawing circles with a pencil. A child "becomes able to identify and label isolable parts of such an experience - the pencil, the paper, the act of drawing, etc" (Fillmore, 1977: 62). As the child starts to recognize the names of all of these associated elements, it is already familiarized with complete frames for different experiences consociated with a pencil. Fillmore decided "to use the word frame for referring to any system of linguistic choices (the easiest cases being collections of words, but also including choices of grammatical rules or grammatical categories - that can get associated with prototypical instances of scenes)" (Fillmore, 1977: 63).

Scenes, however, are being built by the translator. Depending on his "personal experience" and "knowledge of the source language and culture" (Snell-Hornby, 2006: 110) the effects may vary and the translation may be a bit different, for example in the context of the ST author's intentions. The scenes are activated by the translator and the next step is to "find suitable frames in the target language" (Snell-Hornby, 2006: 110). According to Ch. J. Fillmore, a scene may "include not only visual scenes but familiar kinds of interpersonal transactions, standard scenarios, familiar layouts . . . and, in general, any kind of coherent segment large or small, of human beliefs, actions, experiences or imaginings" (Fillmore, 1977: 63).

According to $\mathrm{Ch}$. J. Fillmore, the understanding of the frame is usually subordinate to the perspective. A good example can be a description of a commercial action, where different activities can be observed. Depending on the point of view, one of these activities can be registered in a particular sentence and others may not. For example in the phrase: "John bought the sandwich from Henry for three dollars" the perspective is much different than in a phrase: "Henry sold John the sandwich for three dollars" (Fillmore, 1977: 59). In this case, frames "presuppose a fairly complete understanding of the nature of the total transaction or activity" and "determine a particular perspectival anchoring among the entities involved in the activity" (Fillmore, 1977: 59). What is more, the scenes-and-frames approach is focused on distinguishing different "levels of conceptual frameworks for events: the one giving a general representation of all of the essential aspects of events of a particular category; and the other giving the particular perspective on an event of the type dictated by a case frame" (Fillmore, 1977: 59). This is why the scenes-and-frames theory is so closely connected with the notion of TC. The idea of TC is indeed to analyse and compare the holistic approach to ST and TT and the process of translation. The scheme suggested by $\mathrm{Ch}$. J. Fillmore is a helpful tool to understand the overall nature of both texts. 


\section{Linguistic coherence and translation criticism}

As S. Blum-Kulka claims, coherence "can be viewed as a covert potential meaning relationship among parts of a text, made overt by the reader or listener through processes of interpretation" (Blum-Kulka, 2004: 298-299). Linguistic coherence is a translator's target and a great measure of the translation effects. "The more cohesive, the more formalised is a text, the more information it has as a unit, better affords for the translator" (Newmark, 1988: 55). Translator's work, however, is strongly connected with maintaining coherence too. The meaning is the most important element that has to be conveyed by the translator, but whether ST and TT are coherent, the effect of translator's or interpretor's efforts is greater.

Coherence is also equated with "the text's interpretability" (Blum-Kulka, 2004: 304), which is the main point of TC. According to Blum-Kulka (2004), coherence can be divided into the reader-focused and the text-focused approaches, and the second one is more concerned on the process of translation. "Text-based shifts of coherence often occur as a result of particular choices made by a specific translator, choices that indicate a lack of awareness on the translator's part of the SL's text meaning potential" (Blum-Kulka, 2004: 309). These choices, earlier equated with moves in the game, are translator's actions that are analysed in the TC process. The way the meaning of ST has been conveyed to TT is one of the most important elements examined by a translation critic, and coherence is a great measure of achieving this important goal.

\section{Conclusions and suggestions}

Translation criticism is a field of translation studies that has been properly discovered yet. The task of TC is to make an analysis and an assessment of the product of the translation process providing for comparing ST and TT. TC should be examined seriously, indeed, for it is a great way of explaining how accurate the process of translation is.

The notion and main principles of TC can be understood on the basic of the scenesand-frames theory, which has been developed by Charles J. Fillmore. According to this approach both ST and TT with their elements can be divided into scenes and frames, which are helpful in understanding their nature and comparing them within the TC process.

Although there are different proposed ways of applying TC, all of them can become a very helpful tool in improving the process of translation and translation studies in general. As coherence is a goal of every translator, TC should be applied as often as possible. Developing this field of translation studies is a good way to amend the translation process in general.

\section{References}

Babelyuk, O. (2017). Culture Strategy in Translating Postmodern Literary Text. Scientific Journal of Polonia University, 22(3), 23-26. DOI: 10.23856/2202. [in English].

Babelyuk, O., \& Galaidin, A. (2018). The DAO of Ecotranslation in Polish and Ukrainian Translation Studies. Scientific Journal of Polonia University, 28(3), 91-100. DOI: 10.23856/2811. [in English].

Blum-Kulka, S. (2004). Shifts of Cohesion and Coherence in Translation. [in:] Venuti, L. (Ed.). The Translation Studies Reader. London and New York: Routledge. [in English]. 
Fillmore, Ch. J. (1977). Scenes-and-frames semantics, [in:] Zampolli, A. (Ed.). Linguistic Structures Processing. Amsterdam, New York and Oxford: North Holland Publishing Company. [in English].

Lambert, J., \& Van Gorp, H. (1985). On Describing Translation, [in:] Hermans, T. (Ed.). The Manipulation of Literature. Studies in Literary Translation. New York: Saint Martin's Press. [in English].

Levý, J. (2004). Translation as a Decision Process, [in:] Venuti, L. (Ed.). The Translation Studies Reader. London and New York: Routledge. [in English].

Maier, C. (2009). Reviewing and Criticism, [in:] Baker, M., Saldanha, G. (Eds.). Routledge Encyclopedia of Tramslation Studies. London and New York: Routledge. [in English].

Newmark, P. (1988). A Textbook of Translation. London: Prentice Hall. [in English].

Snell-Hornby, M. (2006). The Turns of Translation Studies: New Paradigms or Shifting Viewpoints? Amsterdam and Philadelphia: John Benjamins. [in English].

Valero, C. (1995). Translation Criticism as an Independent Area of Study: Developing a Framework for Objective Criticism. Livius, 7, 201-212. [in English].

Vermeer, H. J. (1998). Didactics of Translation, [in:] Baker, M., Malmkjaer, K. (Eds.). Routledge Encyclopedia of Translation Studies. London and New York: Routledge. [in English]. 